\title{
Assessment of Wave Energy in the South China Sea Based on GIS Technology
}

\author{
Gang Lin, ${ }^{1,2}$ Long Tan Shao, ${ }^{1}$ Chong Wei Zheng,, ${ }^{2,34}$ Xiao Bin Chen, ${ }^{2}$ Li Feng Zeng, \\ Zhi Hong Liu, ${ }^{2}$ Rong Bo Li, ${ }^{2}$ and Wei Lai Shi ${ }^{3}$ \\ ${ }^{1}$ State Key Laboratory of Structural Analysis for Industrial Equipment, Department of Engineering Mechanics, \\ Dalian University of Technology, Dalian 116085, China \\ ${ }^{2}$ No. 92538 Army of People's Liberation Army, Dalian 116041, China \\ ${ }^{3}$ College of Meteorology and Oceanography, People's Liberation Army University of Science and Technology, Nanjing 211101, China \\ ${ }^{4}$ Dalian Naval Academy, Dalian 116018, China
}

Correspondence should be addressed to Gang Lin; lin_gang@mail.dlut.edu.cn

Received 19 September 2016; Revised 1 January 2017; Accepted 24 January 2017; Published 20 February 2017

Academic Editor: Annalisa Cherchi

Copyright (C) 2017 Gang Lin et al. This is an open access article distributed under the Creative Commons Attribution License, which permits unrestricted use, distribution, and reproduction in any medium, provided the original work is properly cited.

China is now the world's largest user of coal and also has the highest greenhouse gas emissions associated with the mining and use of coal. Under today's enormous pressures of the growing shortage of conventional energy sources and the need for emission reductions, the search for clean energy is the most effective strategy to address the energy crisis and global warming. This study utilized satellite remote sensing technology, geographic information system (GIS) technology, and simulated wave data for the South China Sea. The characteristic features of the wave energy were obtained by analysis through the wave resource assessment formula and the results were stored in a GIS database. Software for the evaluation of wave energy in the South China Sea was written. The results should provide accurate, efficient references for wave energy researchers and decision-makers. Based on a $24-$ year WW3 model simulation wave data and GIS technology, this study presented the characteristic of the wave energy in the SCS; results demonstrated that the SCS has the feasibility and viability for wave energy farming.

\section{Introduction}

China is now the world's largest user of coal and also has the highest greenhouse gas emissions associated with the mining and use of coal [1]. Under today's enormous pressures of the growing shortage of conventional energy sources and the need for emission reductions, the search for clean energy is the most effective strategy to address the energy crisis and global warming $[2,3]$. At present, solar energy $[4,5]$, wind energy [6], and hydrogen energy $[7,8]$ are being thoroughly researched and developed, while ocean energy is still at the exploration stage. Compared with wind and solar technology, wave power generation technology is at least a dozen years behind, but it offers unique advantages [9]. The wave power density (WPD) is high, 4-30 times that of wind energy. Compared with solar energy, wave energy is not seriously affected by the weather. The size of the waves increases with the fetch. Strong winds mean greater waves. As waves grow bigger they also catch more wind, driving them faster and with more energy [10]. Wave energy is believed to be a very large, renewable, environmentally friendly energy source and hence it is currently one of the sources most sought after by developed countries [11, 12]. However, the wave energy distribution of the ocean around the world is not balanced, while in open ocean the wave energy is higher, for example, the northeastern part of the North Atlantic, the south coast of Australia, Chile in South America, the Pacific west coast of North America, and the southwest coast of South Africa [13]. In semiopen or closed seas the wave reserves may be relatively barren, for example, the Mediterranean Sea [14, 15]. But related study shows that, despite relatively lower wave energy compared with open ocean, the semiopen sea can still get considerable economic benefits [14-16]. Although some studies have been made on the distribution of wave energy 
levels around the world and the wave energy distribution of some hot spots has been studied, the reasons of the cause of regional wave energy distribution change are not discussed in depth. Therefore, it is necessary to intensify scientific research, conduct comprehensive resource assessment in the relevant area of wave energy development, and make a systematic analysis of energy distribution and development constraints. South China Sea belonging to this area should be focused on.

The South China Sea, situated in the Western Pacific, extends in a northeast-southwest direction. It is connected to the Pacific and Indian Oceans via the Bashi Channel, the Sulu Sea, and the Malacca Straits. Its southwestern boundary is Vietnam and the Malay Peninsula. The Annam mountains runs parallel to the Vietnamese coast, in a gentle curve which divides the basin of the Mekong River from Vietnam's narrow coastal plain along the South China Sea. Under the influence of the East Asian monsoon, the South China Sea wind field is mostly from a southwesterly direction in the summer, whereas the prevailing wind is northeasterly in the winter [17-20]. The seasonal sea surface wind field drives the upper-layer seasonal circulation of the atmosphere over the South China Sea and also mesoscale cyclonic vortices. Mountains perturb airflow and impact the surface winds and the ocean processes [21], which has been reported in many regions, such as Hawaii Islands [22], Central America [22], Arabian Sea [23], Hainan Islands [24], Gulf of Thailand [25], and Southeast Pacific [26]. The Annam mountains range enhances the warp wind in winter and the zonal wind in summer; the southeast coast of Indo-China forms a highwind area in the summer and winter [27]. Almost the entire South China Sea is surrounded by continents, peninsulas, and islands. According to the density of population and the rapid economic growth, the study and development of wave energy in the South China Sea have important practical significance to the neighboring countries, especially China.

Previous studies have played a significant role in promoting the development and utilization of wave energy resources of the South China Sea. Wan et al. [28] evaluated wave energy resource assessment based on an AVISO multisatellite merged radar altimeter data. Osinowo et al. [29] described long-term spatiotemporal trends in extreme significant wave height (SWH) in the South China Sea. Mirzaei et al. [30] evaluated wave energy potential assessment in the central and southern regions of the South China Sea and pointed that highest annual wave power can be found in the northern region of study area. Zheng and Li [31] have provided the long-term variations of the sea surface wind speed (WS) and significant wave height (SWH). Zheng et al. [32] have also realized the numerical forecasting experiment of the China seas.

With the birth of geographic information system (GIS) technology, people's awareness of spatial information has taken a leap forward. Nowadays, GIS tools have applications in a number of earth and science disciplines [33, 34], either because of their potentialities in the exploitation of topographic information or because of their capability to visualize results on maps $[35,36]$. Since energy research is closely associated with information about geographic locations, GIS technology has major prospects for application in this field [37, 38]. Shafiullah et al. [39] described that GIS provides numbers of tools for analyzing and making decisions in almost each and every sector of traditional power system industry such as in planning of new generating sites, determining optimal routing for transmission networks, and finding suitable places of distribution substations. Shafiullah et al. [39] also evaluated that GIS plays very important roles in management of renewable energy resources by optimizing assets while considering geographical, environmental, socioeconomic, and technical aspects. However, up to now, no research has been done utilizing GIS technology in the South China Sea. Therefore, it is necessary to study the wave energy of the South China Sea in the framework of GIS.

The rest of this paper is organized as follows. The wave model, experimental design, and observational data sets used for verification are given in Section 2. The results and discussion are stated in Section 3, and Section 4 concludes the paper.

\section{Materials and Methods}

2.1. Simulation Methods and Data Sets. This study uses the Cross-Calibrated, Multi-Platform (CCMP) wind production to drive WAVEWATCH-III (WW3) numerical wave model to simulate the wave field in the South China Sea. The WW3 was developed by the Marine Modeling and Analysis Branch (MMAB) of the Environmental Modeling Center (EMC) of the National Centers for Environmental Prediction (NCEP). It is based on WAVEWATCH-I and WAVEWATCHII as developed at Delft University of Technology and NASA Goddard Space Flight Center, respectively [40, 41]. The CCMP wind data have high resolution and high precision, and the CCMP ocean surface wind product is widely used in the evaluation of wind energy resources [42]. The simulations of the sea wave field were performed that provided long time series with a high temporal and spatial resolution for the South China Sea and surrounding sea areas. The simulation area covered a range of $0.125^{\circ}-40.25^{\circ} \mathrm{N}$ and $100.125^{\circ}-$ $135.125^{\circ} \mathrm{E}$. A subarea of the South China Sea defined by the range $0.0^{\circ}-30.0^{\circ} \mathrm{N}$ and $100.0^{\circ}-125.0^{\circ} \mathrm{E}$ was selected, as shown in Figure 1. The spatial resolution was $0.2^{\circ} \times 0.2^{\circ}$, the time interval was $900 \mathrm{~s}$, and the output was generated every $3 \mathrm{~h}$. The duration of the simulation was from January 1, 1988, 00:00 to December 31, 2011, 18:00.

2.2. Data Validation. The simulated data have been validated with high precision by Zheng et al. [42]. Previous studies also have shown that the WW3 model can simulate the SCS very well [43]. In the present study, the wave simulation data were validated using wave buoy observation data from stations at Hualien $\left(24.04^{\circ} \mathrm{N}, 121.63^{\circ} \mathrm{E}\right)$ stations in Taiwan and Dongsha $\left(21.04^{\circ} \mathrm{N}, 118.83^{\circ} \mathrm{E}\right)$ stations in Taiwan in the year 2011. The validation results are shown in Figures 2 and 3 . These figures show a comparison of the fluctuations of the simulated and observed SWH over time. In physical oceanography, the SWH is defined traditionally as the mean wave height of the highest third of the waves $\left(H_{1 / 3}\right)$. It is commonly used as a measure of the height of ocean waves. For the purpose of 


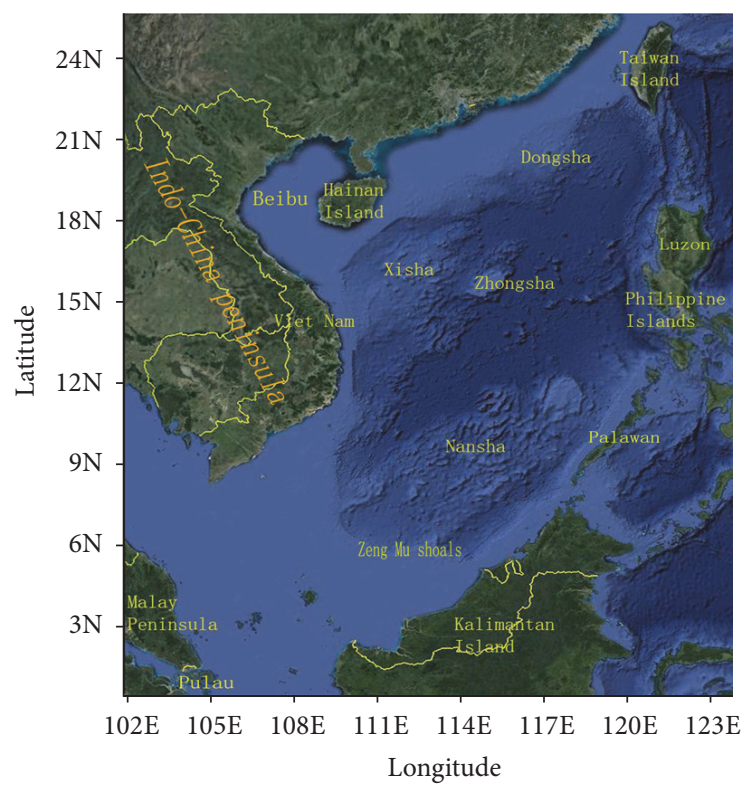

FIgURE 1: Geography of the South China Sea.

quantitative analysis and prediction of the precision of the simulated SWH, the correlation coefficient (CC), bias, root mean square error (RMSE), and mean absolute error (MAE) also have been calculated. The correlation of the simulated SWH and observed SWH values for the Hualien and Dongsha stations is above 0.8 judging from the CC, which passes the $99.9 \%$ reliability test. The deviations for the two stations are all positive and relatively small; this indicates that the observed values are slightly larger than the simulated values. The RMSE and MAE values are very small, indicating that the errors are small and all within a controllable range. Figure 2 shows that the SWH of the Hualien station was within $4.0 \mathrm{~m}$ in January and October. Figure 3 shows that in these same months the SWH of the Dongsha station was within $6.0 \mathrm{~m}$. This may be partially explained by the fact that in January and October the South China Sea is influenced significantly by the northeasterly monsoon. The terrain of the island of Taiwan provides better wind shelter for the Hualien than for the Dongsha station. Naturally, under the influence of strong cold winds in winter, the wave height is higher at the Dongsha station than at the Hualien station. In conclusion, this simulation of the wave field in the South China Sea as a whole has high precision.

2.3. Analysis Methods. With reference to the United States Electric Power Research Institute (EPRI) wave resource assessment formula, this paper calculated the wave power density $[44,45]$ :

$$
\begin{aligned}
P_{w} & \approx 0.42 \times H_{1 / 3}^{2} \times T_{p} \\
\text { or } P_{w} & \approx 0.5 \times H_{1 / 3}^{2} \times \bar{T},
\end{aligned}
$$

where $P_{w}$ is the wave power density, $H_{1 / 3}$ is the SWH, $T_{p}$ is the peak wave period, and $\bar{T}$ is defined for the average cycle by $T_{p}=1.2 \bar{T}$. Using the above formula, Roger [45] made a successful prediction of the wave power density for the east Pacific coast.

Four aspects of the wave power density in the South China Sea were considered: seasonal characteristics, power level frequencies, stability, and an integrated assessment of wave power.

Cornett pointed out that the dispersion or stability of data has to be taken into account in the process of developing wave energy resources [46]. The stability of the power density affects not only resource acquisition and the conversion efficiency, but also the life expectancy of equipment. As a result, it also affects the cost significantly.

To judge the stability of the wave power density, this paper calculated the coefficient of variation $\left(C_{v}\right)$ of wave power density in different months, using the wave energy data simulated every $3 \mathrm{~h}$ from January 1, 1988, 00:00 to December 31, 2011, 18:00. The conclusion was that the coefficient of variation is small and the stability is good. $C_{v}$ can be calculated as follows:

$$
C_{v}=\left(\frac{d_{s}}{\bar{x}}\right) \times 100 \%,
$$

where $\bar{x}$ is the average wave power density; $d_{s}$ is the standard deviation:

$$
d_{s}=\sqrt{\frac{\sum_{i=1}^{n} x_{i}^{2}-\left(\sum_{i=1}^{n} x_{i}\right)^{2} / n}{n-1}} .
$$

With every 3-hour wind power density in January from 1988 to 2011, the stability of annual wind power density in the recent 24 years was calculated.

In the evaluation of the wave energy resources, an energy level frequency is an important criterion to measure the richness of wave energy resources. Typically, a power density higher than $2 \mathrm{~kW} / \mathrm{m}$ is considered as eligible for practical exploitation in the evaluation of the wave energy resources and the area of higher than $20 \mathrm{~kW} / \mathrm{m}$ is considered as a rich region [42], such as the South Atlantic.

\section{Results and Discussion}

3.1. Seasonal and Annual Characteristics of Wave Power Density. In the MAM (March, April, and May) (Figure 4(a)), the wave power density is $2-8 \mathrm{~kW} / \mathrm{m}$ for most of the SCS waters. However, near the equator and the Beibu Gulf, the wave power density is around $1 \mathrm{~kW} / \mathrm{m}$. The maximum value, 9-11 kW/m, is located in the southeastern area of the Dongsha archipelago. The wave power density is only $3-6 \mathrm{~kW} / \mathrm{m}$ in the south and is lower still, at about $1-2 \mathrm{~kW} / \mathrm{m}$, close to the equator near the Zeng Mu shoals. From the location of the maximum value in the southeastern Dongsha archipelago, the wave power density decreases gradually toward the Malacca Straits. It decreases rapidly from the location of the maximum value toward Luzon, Taiwan, and mainland Asia. The wave power density is larger in the geographical regions of Dongsha, Zhongsha, and Xisha than it is in the Nansha area.

In the JJA (June, July, and August) (Figure 4(b)), the wave power density shows a pattern that is extended in a northeastsouthwest direction. Under the influence of the southwest 


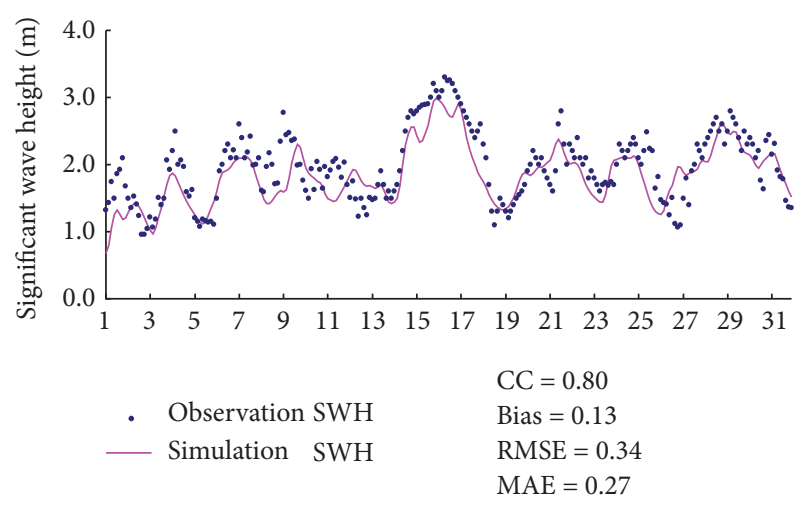

(a)

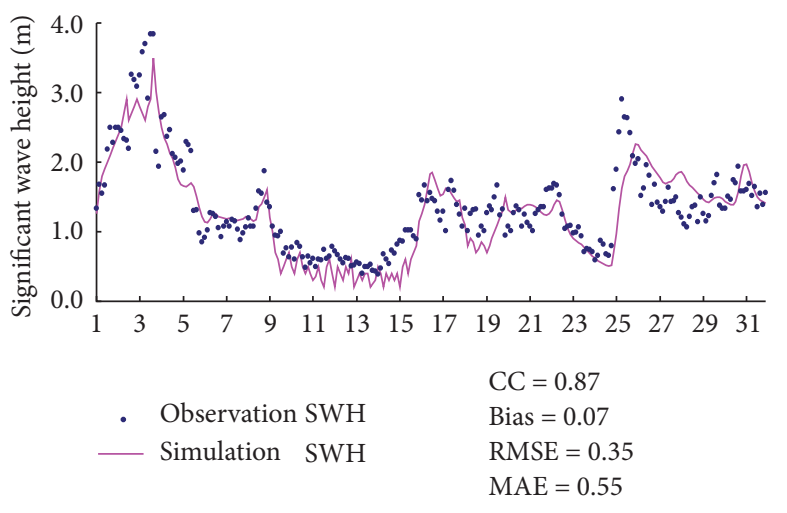

(b)

FIGURE 2: The simulated and observed significant wave height at Hualien for year 2011, month 1 and month 10. Unit: $\mathrm{m}$.

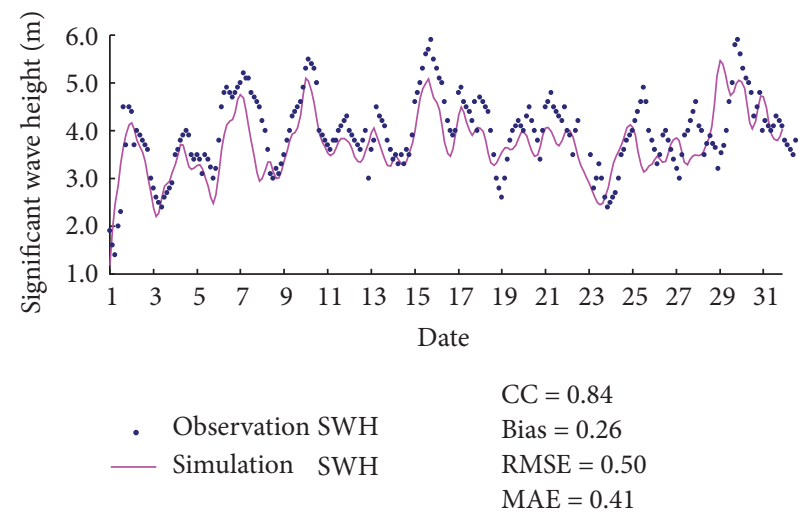

(a)

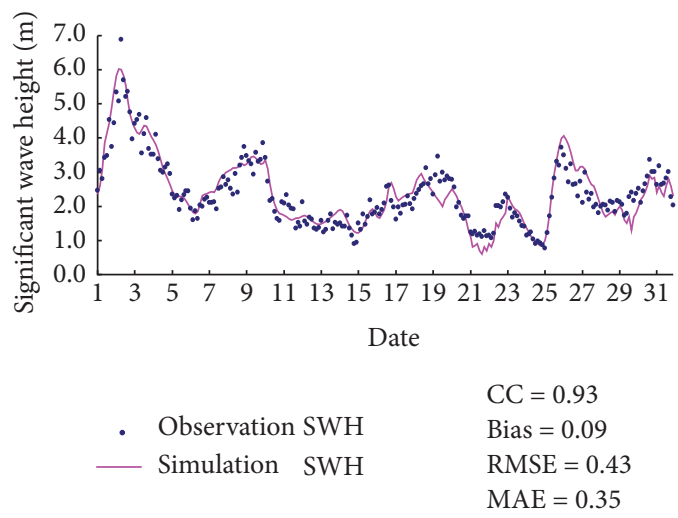

(b)

FIgURE 3: The simulated and observed significant wave height at Dongsha for year 2011, month 1 and month 10. Unit: $\mathrm{m}$.

monsoon, the wave power density is $6 \mathrm{~kW} / \mathrm{m}$ or more in most areas of the South China Sea. The maximum value is located to the east of the Indo-China peninsula [43], with a value of about $8 \mathrm{~kW} / \mathrm{m}$ or above. From the location of maximum value toward Taiwan, the wave power density is around 7$8 \mathrm{~kW} / \mathrm{m}$. In the directions toward Indo-China, Kalimantan, Pulau, Luzon, and Palawan, the wave power density decreases evenly and rapidly. For the waters near the equator and the Beibu Gulf, the wave power density is still at around $1 \mathrm{~kW} / \mathrm{m}$. The wave power density is larger in the geographic areas of Dongsha, Zhongsha, and the Nansha Islands than in the Xisha Islands.

In the SON (September, October, and November) (Figure 4(c)), in most areas of the South China Sea, the wave power density is about $9-27 \mathrm{~kW} / \mathrm{m}$. The maximum value, about $21-27 \mathrm{~kW} / \mathrm{m}$, is located in the waters near Dongsha. The region of maximum wave power density $(>21 \mathrm{~kW} / \mathrm{m})$ lies in a southwest-northeast direction toward the Luzon Strait. From the location of the maximum value to Taiwan, Luzon, and the Asian continent, it decreases evenly and rapidly. Toward the Indo-China peninsula and Kalimantan, it decreases gradually and slowly. Around the Zeng Mu shoals, the value is lower, at around $3 \mathrm{~kW} / \mathrm{m}$. Near the equator and the Beibu Gulf, the wave power density is about $1 \mathrm{~kW} / \mathrm{m}$. The wave power density is larger in the geographical regions of Dongsha, Zhongsha, and Xisha than in the Nansha area. But, compared with spring and summer, the wave power density is larger across the whole region.

In the DJF (December, January, and February) (Figure 4(d)), under the influence of strong cold winds, the wave power density is near its maximum all year round, at around $15-27 \mathrm{~kW} / \mathrm{m}$. Two obvious high-value centers can be observed: the Luzon Strait and the SCS high-wind-speed area. In both of these high-value centers, the region of maximum wave power density $(>21 \mathrm{~kW} / \mathrm{m})$ shows a pattern that is extended in a southwest-northeast direction. The wave power density is higher than $24 \mathrm{~kW} / \mathrm{m}$ in the SCS high-wind-speed area and above $27 \mathrm{~kW} / \mathrm{m}$ in the Luzon Strait area. From the Luzon Strait area to Luzon Island, Taiwan, and the Asian continent, it decreases evenly and rapidly. Toward the Indo-China peninsula, it shows a slow, steady decrease. From the SCS high-wind-speed area to the Indo-China area, it decreases rapidly and evenly. It shows a slow, steady decrease in the directions of Kalimantan, Pulau, and the Malay Peninsula. In the equatorial area and around the Beibu Gulf, the wave power density remains low, at about 


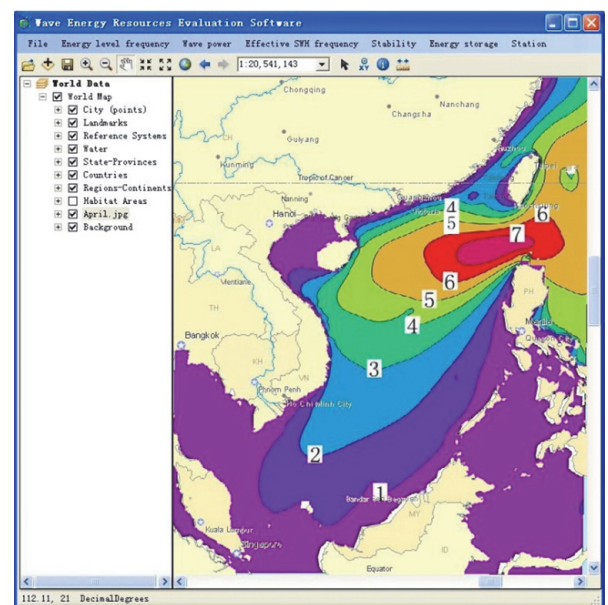

(a)

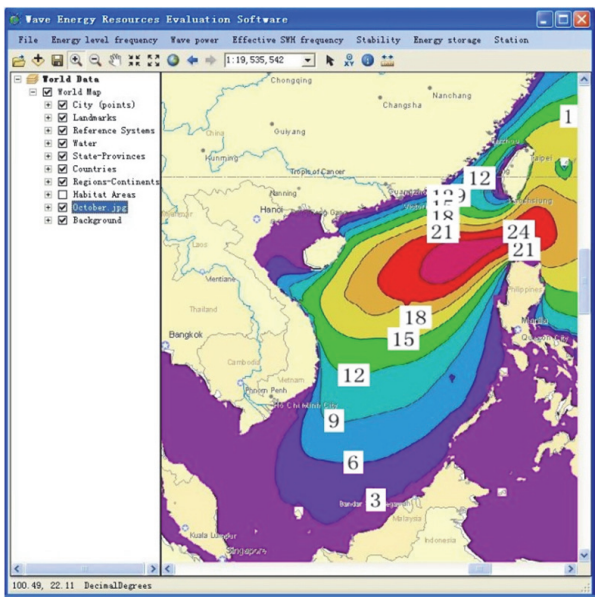

(c)

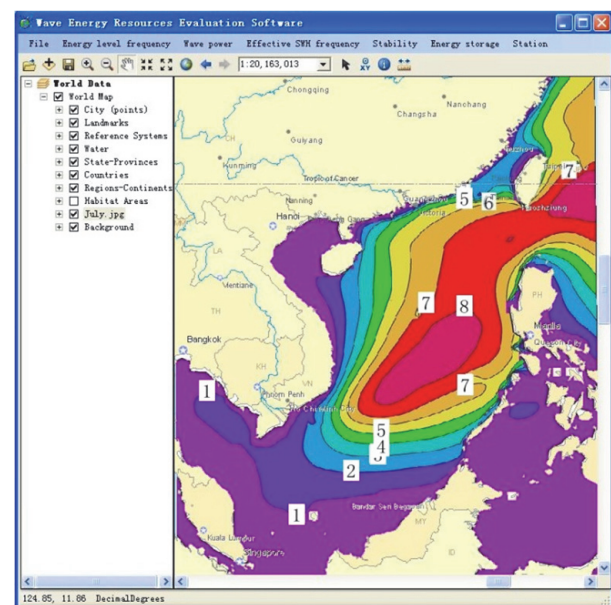

(b)

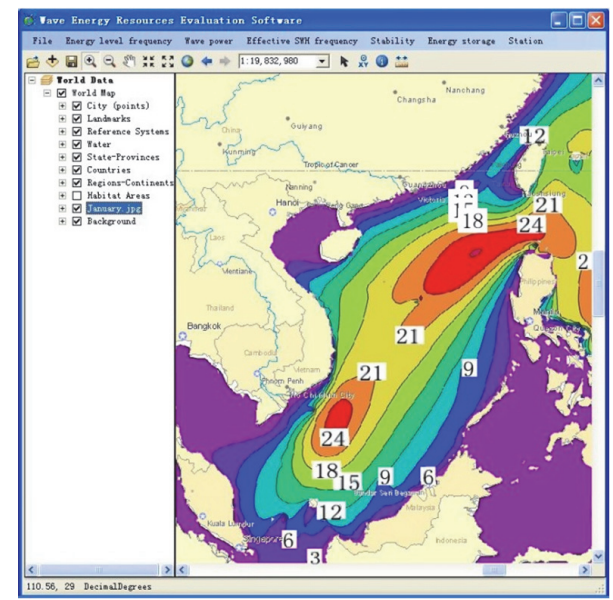

(d)

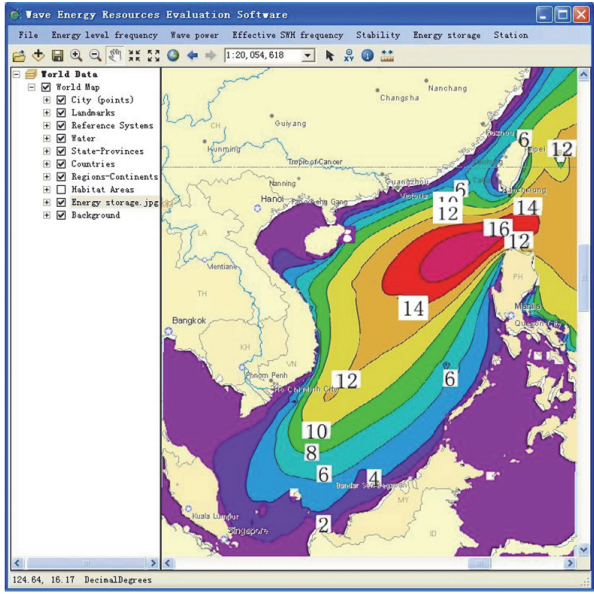

(e)

FIGURE 4: The seasonal and annual average wave power densities in the South China Sea. (a) Spring, (b) summer, (c) autumn, (d) winter, and (e) annual average. Unit: $\mathrm{kW} / \mathrm{m}$. 


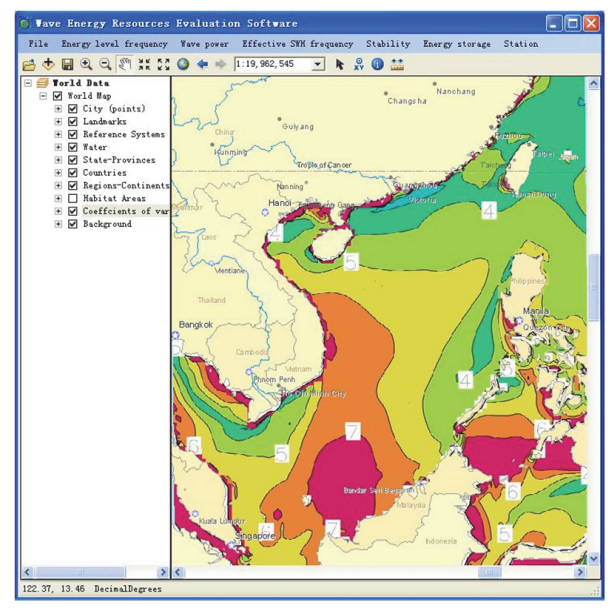

Figure 5: The $C_{v}$ of wave power density in the South China Sea (percentage \%).

$1 \mathrm{~kW} / \mathrm{m}$. Geographically, the wave power density is higher in the areas of Dongsha, Zhongsha, Xisha, and the Nansha Islands; seasonally, the wave power density is at its highest level in the winter.

The pattern of the annual average wave power density (Figure $4(\mathrm{e})$ ) is extended in a northeast-southwest direction. The maximum value of the wave power density is located to the southeast of Dongsha and exceeds $18 \mathrm{~kW} / \mathrm{m}$. The wave power density shows a slow, even descent (gradient descent) from the Luzon Strait to Peninsular Malaysia; to the southeast of the Indo-China Peninsula, it remains at $12 \mathrm{~kW} / \mathrm{m}$ or above. In the entire South China Sea, only the Beibu Gulf and areas near the equator have low values of the wave power density, about $2 \mathrm{~kW} / \mathrm{m}$.

3.2. Stability of Wave Power Density. As shown in Figure $5, C_{v}$ of the South China Sea wave energy varies from $4 \%$ to $7 \%$. In the northern area of the South China Sea, the adjacent waters of Taiwan Island, Beibu Gulf, $C_{v}$ is about $4 \%$. In the western waters of Luzon, the western waters of Kalimantan, $C_{v}$ is between $4 \%$ and 5\%. From the Luzon Strait toward the South China Sea high-wind-speed area, $C_{v}$ increases gradually and evenly. The area with relatively high value is distributed in the northern area of the South China Sea. In the Indo-China Peninsula's southeast, $C_{v}$ is stable at $7 \%$. In the South China Sea high-wind-speed area, $C_{v}$ reaches $8 \%$.

The stability in the northern area of the South China Sea is better than that in other areas. As described above, the resource acquisition and the conversion efficiency in the northern area of the South China Sea is better than that in other areas, and the life expectancy of equipment is longer than that in other areas. So, the northern area of the South China Sea is the most appropriate area for the exploitation of wave energy resources.

3.3. Frequency of Effective SWH. The statistics indicated that, in the South China Sea overall, the frequency of power densities greater than $2 \mathrm{~kW} / \mathrm{m}$ is very high (Figure 6). And the power density has a stable distribution, with a pattern

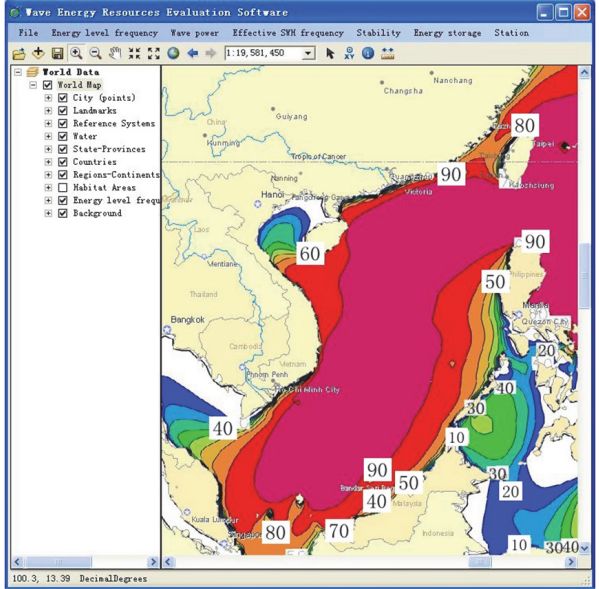

FIGURE 6: The frequency of wave power densities above $2 \mathrm{~kW} / \mathrm{m}$ in the South China Sea (percentage \%).

extending in a northeast-southwest direction. This frequency is around $90 \%$ in most of the waters in the region. Only in small inshore areas, near the equator and the Beibu Gulf, is the frequency $80 \%$ or less.

3.4. East Asian Monsoon and Topography. Generally, on a longer time scale, from 1988 to 2011, the results discussed above can be considered stable, and the influencing factors can be analyzed from these data. In this paragraph, mainly from the East Asian Monsoon and Annam cordillera, we analyze the reasons of the wave power density, the stability of the power density, and the energy level frequency.

The SCS summer monsoon broke out in mid-May, and the southwest monsoon prevailed in the SCS from June to August. It is worth noting that a strong wind speed region exists in the southeast coast of Vietnam, the west side of the central part of the SCS, and its maximum wind speed is above $8 \mathrm{~m} / \mathrm{s}$. Corresponding to the topographic distribution of the Indo-China Peninsula, the SCS wind jet is located on the southeast side of the south of the Annam Mountains, so the formation should be related to the narrow north-south Annam mountains. It is envisaged that when the strong southwest monsoon approaches the north-south mountain range, the terrain of the mountain will obviously block the strong southwest airstream. Since the average height of the mountain ranges is no more than $1.5 \mathrm{~km}$, most of the southwesterly winds will cross the mountain range, although the mountains will block the southwest airstream. At the same time, some of the southwest monsoon, due to the terrain blocking effect, will bypass the southern tip of the Annam cordillera. Thus, there is a strong wind speed region on the west side of the central part of the SCS, and the maximum wind speed is above $8 \mathrm{~m} / \mathrm{s}$, as shown in Figure 7(a). After September, the southwest wind speed began to weaken rapidly, in October the Vietnamese coast has turned into a consistent northeast monsoon, and the wind speed in December to January gradually increased to reach its strongest. Due to the blockage of the Annam cordillera, the northeast monsoon prevailing in winter is turned to 


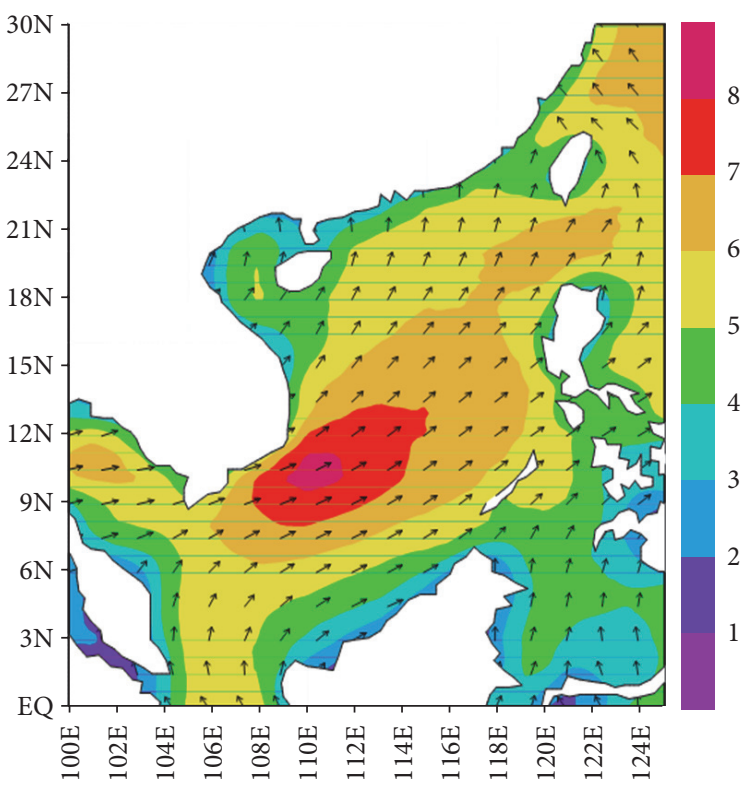

(a)

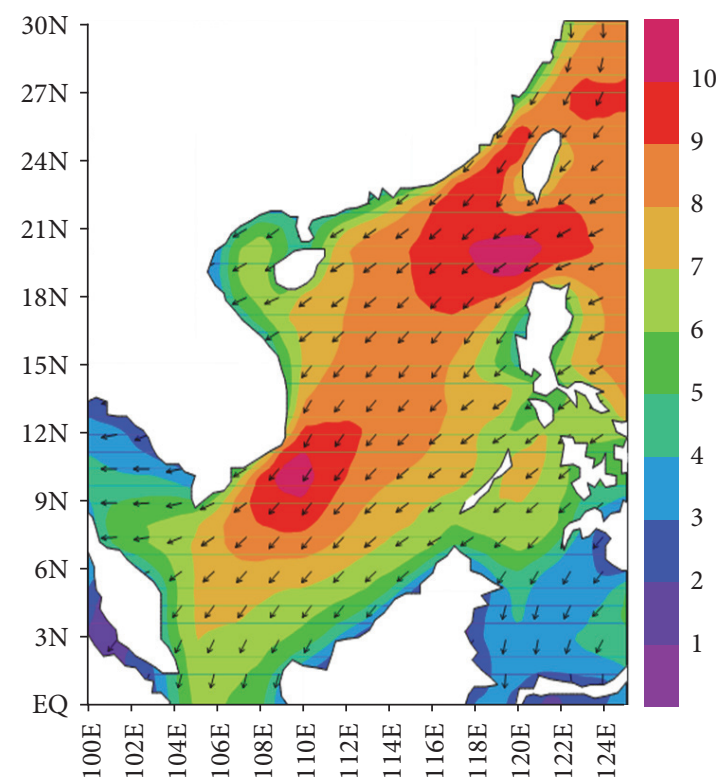

(b)

Figure 7: The monthly mean wind speed in the South China Sea. (a) August. (b) January. Unit: m/s.

north-northeast when it is close to the southeastern coast of Vietnam, and a strong wind velocity region of $11 \mathrm{~m} / \mathrm{s}$ was formed along the southeast coast of Vietnam, as shown in Figure 7(b). It can be seen that the long and narrow mountains have an important influence on the summer wind field and winter wind field distribution in the South China Sea.

Through the above analysis, we can see that the SCS wave power density distribution closely related to the East Asian Monsoon and topography. As Figure 4(b) shows the maximum value is located to the southeast of the Indo-China peninsula in the JJA, consistent with the summer southeast monsoon wind area. As Figure 4(b) shows there are two extremes in the distribution of wave power density in the SCS in the DJF; the southwestern extremes coincide with the SCS high-wind area in the southeast of the Annam mountains. Figure 5 shows that the stability in the northern area of the SCS is better than in other areas. This is caused by the change between a northeasterly wind in winter and a southwesterly wind in summer. But the stability in the southern area of the SCS is relatively poor. Because the southern SCS is controlled by strong winds only in the DJF, the power density of the southern SCS is relatively large, and the other times are relatively low.

3.5. Exploitation of the Wave Energy Resources. The statistics indicated that the power density has a stable distribution, with a pattern extending in a northeast-southwest direction, and the wave power density in the Luzon Strait and the Dongsha area is at its maximum value all year round. The wave power density reaches its maximum value in the highwind-speed area southeast of Indo-China in the winter, and it is also high in summer and autumn. So, the whole South
China Sea is appropriate for the exploitation of wave energy resources. But under the influence of the East Asian monsoon and the effect of Annam cordillera in enhancing the winter and summer winds, the stability in the northern area of the South China Sea is better than that in other areas. As described above, the resource acquisition and the conversion efficiency in the northern area of the South China Sea is better than that in other areas, and the life expectancy of equipment is longer than that in other areas. So, the northern area of the South China Sea is the most appropriate area for the exploitation of wave energy resources.

\section{Conclusion}

Based on a 24-year WW3 model simulation wave data and GIS technology, this study presented the characteristic of the wave energy in the SCS; results demonstrated that the SCS has the feasibility and viability for wave energy farming.

(1) The WW3 model presented here can simulate the wave field in the SCS very well and can provide researchers with long time series of stable, reliable research data.

(2) The annual average wave power density in the SCS reaches its maximum value of $18 \mathrm{~kW} / \mathrm{m}$ in the area between Dongsha and the Luzon Strait, peaking in winter at $27 \mathrm{~kW} / \mathrm{m}$. Examining the seasonal factors, the wave power density in the SCS is slightly lower in summer and spring and higher in autumn and winter, but basically above $2 \mathrm{~kW} / \mathrm{m}$ in all seasons.

(3) The stability of the wave power density in the southern and northern regions of the SCS exhibits significant differences. The stability of the power density is better 
in the northern area and $C_{v}$ is small, basically less than 5\%. In the southern SCS, particularly in the highwind-speed area to the southeast of the Indo-China peninsula, the power density is less stable because of the impact of Annam on the winter and summer monsoons. Here, $C_{v}$ is large, reaching $7 \%$ or above.

(4) Over the past 24 years, in most of the SCS region, the frequency of occurrence of power densities greater than $2 \mathrm{~kW} / \mathrm{m}$ has been $90 \%$ or above. Only in small inshore areas, near the equator and the Beibu Gulf, this frequency is $80 \%$ or less.

(5) The long and narrow Annam mountains have an important influence on the summer wind field and winter wind field distribution in the SCS. And the SCS wave power density distribution and stability are closely related to the East Asian Monsoon and Annam cordillera.

(6) Because energy research is closely associated with information about geographic locations, GIS technology has major prospects for application in this field. The GIS database provided accurate and efficient information, which could be used by researchers in wave energy and the decision-makers about resource development.
Abbreviations
CCMP: Cross-Calibrated, Multi-Platform
EPRI: US Electric Power Research Institute
GIS: Geographic information system
IPCC: Intergovernmental Panel on Climate Change
RS: $\quad$ Remote sensing
SCS: South China Sea
SWH: Significant wave height
WW3: WAVEWATCH-III
WPD: Wave power density.

\section{Competing Interests}

The authors declare that they have no competing interests.

\section{Acknowledgments}

This work was supported by the Junior Fellowships for CAST Advanced Innovation Think-Tank Program (entitled "Evaluation of the Oceanic Dynamic Resources of the 21st Century Maritime Silk Road and Its Strategic Points," no. DXB-ZKQN-2016-019), the Major Research Topic of the Propaganda Department of CAST (entitled "Problems and Countermeasures and Suggestions of the Strategic Points Construction of the 21st Century Maritime Silk Road), and the Nature Science Foundation of Shandong Province (no. ZR2016DL09).

\section{References}

[1] W. Li, L. Y. Paul, Y. P. C. Cheng et al., "Addressing the $\mathrm{CO}_{2}$ emissions of the world's largest coal producer and consumer: lessons from the Haishiwan Coalfield, China," Energy, vol. 80, pp. 400-413, 2015.

[2] S. B. Capps and C. S. Zender, "Global ocean wind power sensitivity to surface layer stability," Geophysical Research Letters, vol. 36, no. 9, Article ID L09801, 2009.

[3] S. B. Capps and C. S. Zender, "Estimated global ocean wind power potential from QuikSCAT observations, accounting for turbine characteristics and siting," Journal of Geophysical Research Atmospheres, vol. 115, no. 9, 2010.

[4] V. Balzani, A. Credi, and M. Venturi, "Photochemical conversion of solar energy," ChemSusChem, vol. 1, no. 1-2, pp. 26-58, 2008.

[5] S. K. Ngoh and D. Njomo, "An overview of hydrogen gas production from solar energy," Renewable \& Sustainable Energy Reviews, vol. 16, no. 9, pp. 6782-6792, 2012.

[6] X. T. Chadee and R. M. Clarke, "Large-scale wind energy potential of the Caribbean region using near-surface reanalysis data," Renewable and Sustainable Energy Reviews, vol. 30, pp. 45-58, 2014.

[7] C.-J. Winter, "Hydrogen energy—abundant, efficient, clean: a debate over the energy-system-of-change," International Journal of Hydrogen Energy, vol. 34, no. 14, S1, pp. S1-S52, 2009.

[8] P. Nikolaidis and A. Poullikkas, "A comparative overview of hydrogen production processes," Renewable and Sustainable Energy Reviews, vol. 67, pp. 597-611, 2017.

[9] J. Falnes, “A review of wave-energy extraction," Marine Structures, vol. 20, no. 4, pp. 185-201, 2007.

[10] J. Thomson and W. E. Rogers, "Swell and sea in the emerging Arctic Ocean," Geophysical Research Letters, vol. 41, no. 9, pp. 3136-3140, 2014.

[11] A. Rashid and S. Hasanzadeh, "Status and potentials of offshore wave energy resources in Chahbahar area (NW Omman Sea)," Renewable and Sustainable Energy Reviews, vol. 15, no. 9, pp. 4876-4883, 2011.

[12] J. H. Wilson and A. Beyene, "California wave energy resource evaluation," Journal of Coastal Research, vol. 23, no. 3, pp. 679690, 2007.

[13] K. Hulls, "Wave power," The New Zealand Energy Journal, vol. 50, pp. 44-48, 1977.

[14] G. Besio, L. Mentaschi, and A. Mazzino, "Wave energy resource assessment in the Mediterranean Sea on the basis of a 35-year hindcast," Energy, vol. 94, pp. 50-63, 2016.

[15] G. Emmanouil, G. Galanis, C. Kalogeri, G. Zodiatis, and G. Kallos, "10-year high resolution study of wind, sea waves and wave energy assessment in the Greek offshore areas," Renewable Energy, vol. 90, pp. 399-419, 2016.

[16] A. Mirzaei, F. Tangang, and L. Juneng, "Wave energy potential along the east coast of Peninsular Malaysia," Energy, vol. 68, pp. 722-734, 2014.

[17] D. Yihui and J. C. L. Chan, “The East Asian summer monsoon: an overview," Meteorology and Atmospheric Physics, vol. 89, no. 1-4, pp. 117-142, 2005.

[18] B. Wang, The Asian Monsoon, Springer, Berlin, Germany, 2006.

[19] C. P. Chang, "East Asian Monsoon," World Scientific, vol. 4, no. 2, aerticle 572, 2004.

[20] Y. Ding, C. Li, and Y. Liu, "Overview of the South China Sea Monsoon Experiment," Advances in Atmospheric Sciences, vol. 21, no. 3, pp. 343-360, 2004.

[21] D. B. Chelton, M. G. Schlax, M. H. Freilich, and R. F. Milliff, "Satellite measurements reveal persistent small-scale features in ocean winds," Science, vol. 303, no. 5660, pp. 978-983, 2004. 
[22] S.-P. Xie, W. T. Liu, Q. Liu, and M. Nonaka, "Far-reaching effects of the Hawaiian islands on the Pacific Ocean-atmosphere system," Science, vol. 292, no. 5524, pp. 2057-2060, 2001.

[23] J. Kurian and P. N. Vinayachandran, "Mechanisms of formation of the Arabian Sea mini warm pool in a high-resolution Ocean General Circulation Model," Journal of Geophysical Research: Oceans, vol. 112, no. 5, Article ID C05009, 2007.

[24] J. Li, G. Wang, S.-P. Xie, R. Zhang, and Z. Sun, "A winter warm pool southwest of Hainan Island due to the orographic wind wake," Journal of Geophysical Research: Oceans, vol. 117, no. 8, Article ID C08036, 2012.

[25] J. Li, R. Zhang, Z. Ling, W. Bo, and Y. Liu, "Effects of Cardamom Mountains on the formation of the winter warm pool in the gulf of Thailand," Continental Shelf Research, vol. 91, pp. 211-219, 2014.

[26] H. Xu, S.-P. Xie, and Y. Wang, "Subseasonal variability of the southeast Pacific stratus cloud deck," Journal of Climate, vol. 18, no. 1, pp. 131-142, 2005.

[27] H.-M. Xu, J.-H. He, and S.-P. Xie, "Satellite-revealed effects of Mesoscale Mountains on the summer climate of the South China Sea," Chinese Journal of Atmospheric Sciences, vol. 31, no. 5, pp. 1021-1031, 2007.

[28] Y. Wan, J. Zhang, J. Meng, and J. Wang, "A wave energy resource assessment in the China's seas based on multi-satellite merged radar altimeter data," Acta Oceanologica Sinica, vol. 34, no. 3, pp. 115-124, 2015.

[29] A. Osinowo, X. Lin, D. Zhao, and Z. Wang, "Long-term variability of extreme significant wave height in the South China Sea," Advances in Meteorology, vol. 2016, Article ID 2419353, 21 pages, 2016.

[30] A. Mirzaei, F. Tangang, and L. Juneng, "Wave energy potential assessment in the central and southern regions of the South China Sea," Renewable Energy, vol. 80, pp. 454-470, 2015.

[31] C. W. Zheng and C. Y. Li, "Variation of the wave energy and significant wave height in the China Sea and adjacent waters," Renewable and Sustainable Energy Reviews, vol. 43, pp. 381-387, 2015.

[32] C. W. Zheng, C. Y. Li, X. Chen, and J. Pan, "Numerical forecasting experiment of the wave energy resource in the China Sea," Advances in Meteorology, vol. 2016, Article ID 5692431, 12 pages, 2016.

[33] J. Hossain, V. Sinha, and V. V. N. Kishore, "A GIS based assessment of potential for windfarms in India," Renewable Energy, vol. 36, no. 12, pp. 3257-3267, 2011.

[34] J.-P. K. Lubamba, J. Radoux, and P. Defourny, "Multimodal accessibility modeling from coarse transportation networks in Africa," International Journal of Geographical Information Science, vol. 27, no. 5, pp. 1005-1022, 2013.

[35] V. Demir and O. Kisi, "Flood hazard mapping by using geographic information system and hydraulic model: Mert River, Samsun, Turkey," Advances in Meteorology, vol. 2016, Article ID 4891015, 9 pages, 2016.

[36] D. G. Palomino Cuya, L. Brandimarte, I. Popescu, J. Alterach, and M. Peviani, "A GIS-based assessment of maximum potential hydropower production in La Plata basin under global changes," Renewable Energy, vol. 50, pp. 103-114, 2013.

[37] A. Gemelli, A. Mancini Adriano, and S. Longhi, "GIS-based energy-economic model of low temperature geothermal resources: a case study in the Italian Marche region," Renewable Energy, vol. 36, no. 9, pp. 2474-2483, 2011.
[38] J. Van Hoesen and S. Letendre, "Evaluating potential renewable energy resources in Poultney, Vermont: a GIS-based approach to supporting rural community energy planning," Renewable Energy, vol. 35, no. 9, pp. 2114-2122, 2010.

[39] M. Shafiullah, S. M. Rahman, M. G. Mortoja, and B. Al-Ramadan, "Role of spatial analysis technology in power system industry: an overview," Renewable \& Sustainable Energy Reviews, vol. 66, pp. 584-595, 2016.

[40] H. L. Tolman, "User manual and system documentation of WAVEWATCH-III version 2.22," NOAA/NWS/NCEP/MMAB Technical Note 222, 2002.

[41] H. L. Tolman, "User manual and system documentation of WAVEWATCH-III version 3.14," Technical Note, NOAA/NWS/ NCEP/MMAB, Washington, DC, USA, 2009.

[42] C.-W. Zheng, J. Pan, and J.-X. Li, "Assessing the China Sea wind energy and wave energy resources from 1988 to 2009," Ocean Engineering, vol. 65, pp. 39-48, 2013.

[43] A. Mirzaei, F. Tangang, L. Juneng, M. A. Mustapha, M. L. Husain, and M. F. Akhir, "Wave climate simulation for southern region of the South China Sea," Ocean Dynamics, vol. 63, no. 8, pp. 961-977, 2013.

[44] H. George and B. Roger, "Guidelines for preliminary estimation of power production by offshore wave energy conversion devices," Tech. Rep. E2I/EPRI-WP-001, Electric Power Research Institude (EPRI), 2003.

[45] B. Roger, "Wave energy forecasting accuracy as a function of forecast time horizon," Tech. Rep. E2I/EPRI-WP-013, Electric Power Research Institude (EPRI), Charlotte, NC, USA, 2009.

[46] A. M. Cornett, "A global wave energy resource assessment," in Proceedings of the 18 International Offshore and Polar Engineering Conference, pp. 318-326, The International Society of Offshore and Polar Engineers, Vancouver, Canada, 2008. 

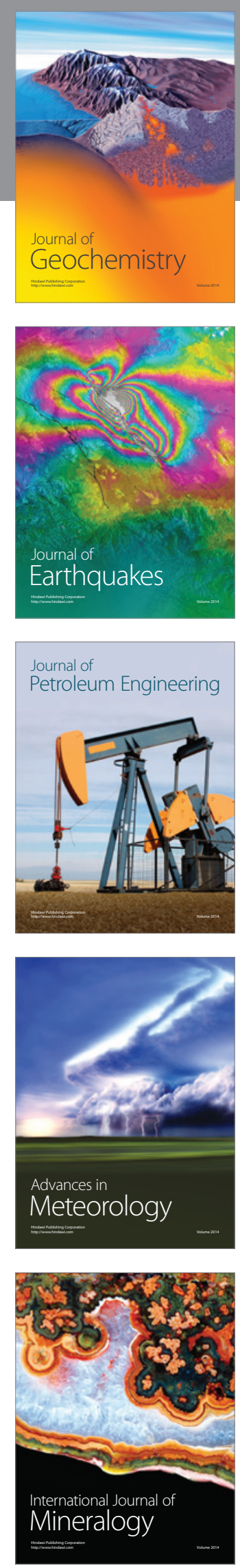
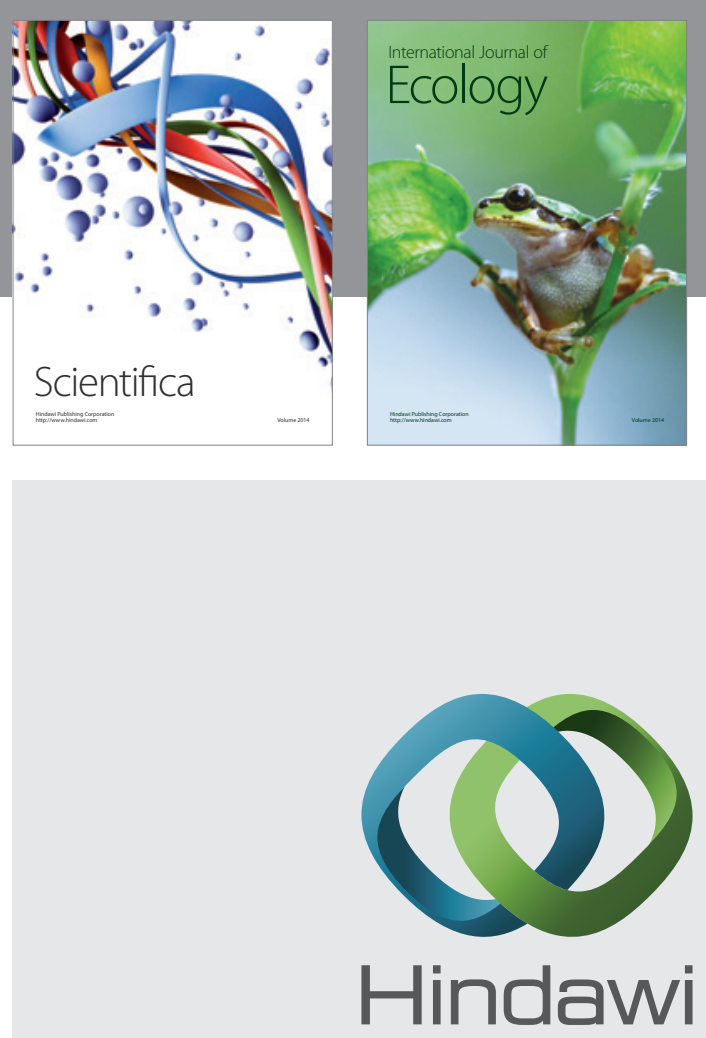

Submit your manuscripts at

https://www.hindawi.com
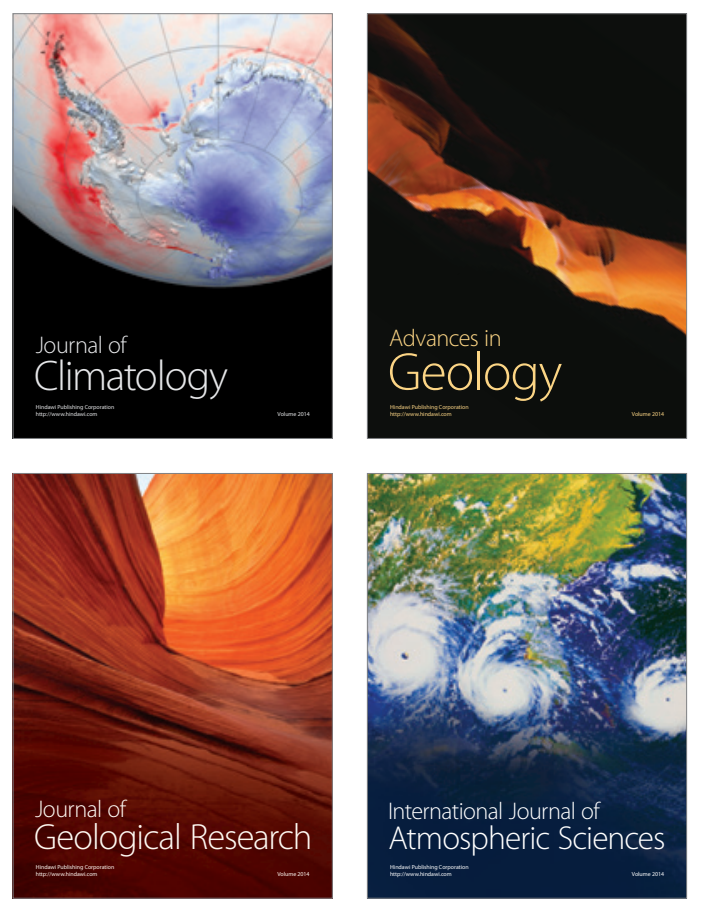

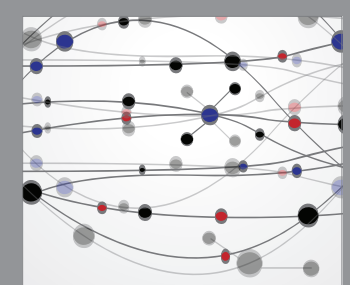

The Scientific

\section{World Journal}
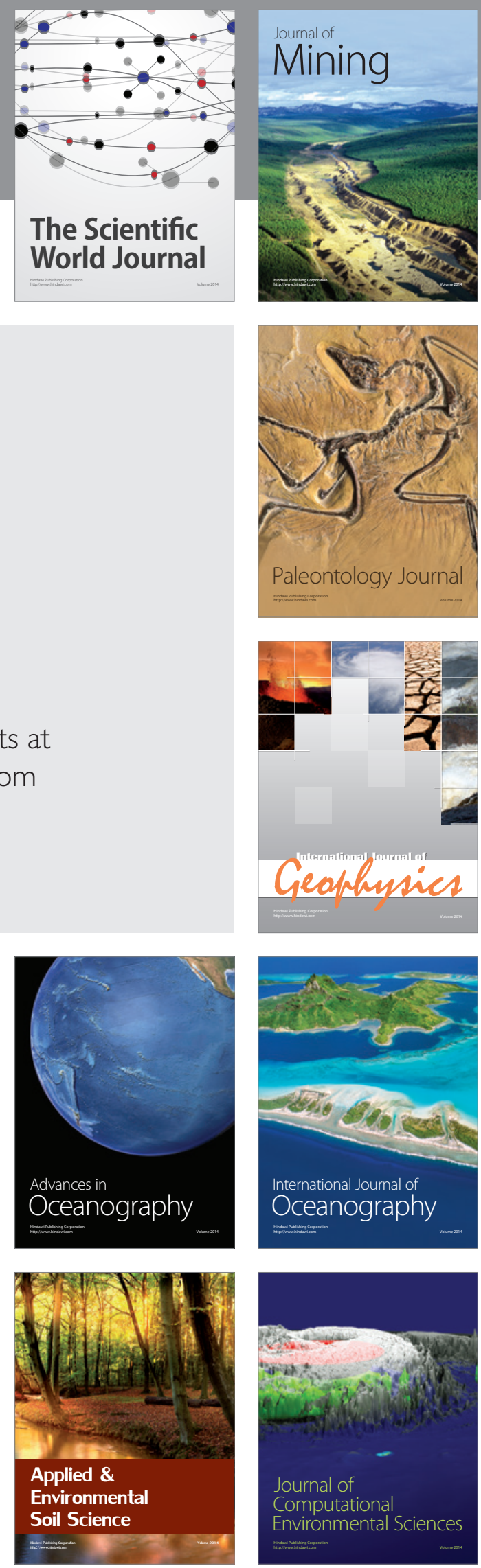